Faculdade de Ciências Econômicas UFRGS
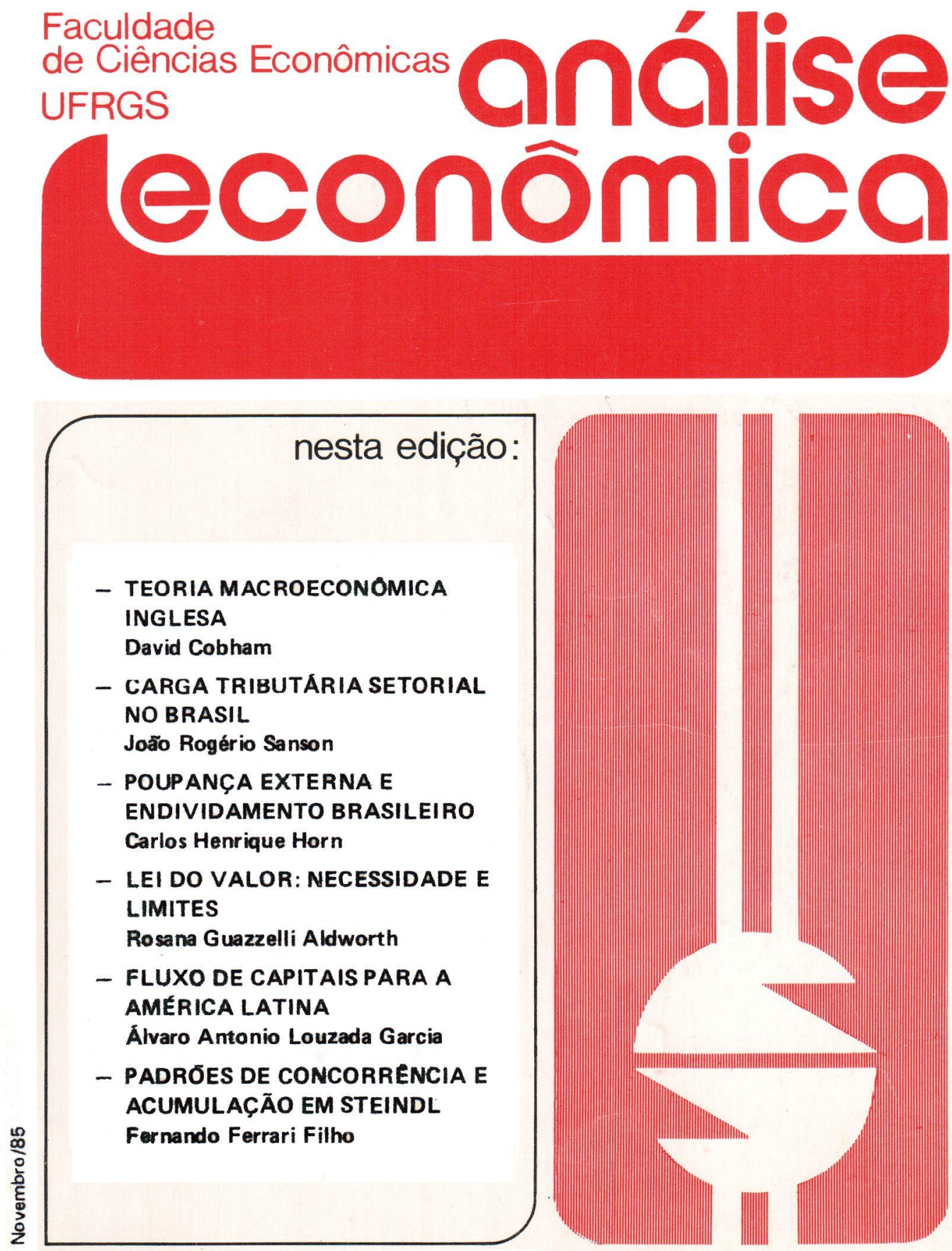

ano 3 
REITOR:Prof. Francisco Ferraz

DIRETOR DA FACULDADE DE CIÊNCIAS ECONÓMICAS:

Prof. Edgar lrio Simm

VICE-DIRETOR: Prof. Walter Meucci Nique

CHEFE DO DEPARTAMENTO DE CIENCIAS ECONOMICAS:

Prof. Renato Batista Masina

CONSELHO EDITORIAL: Prof. Pedro Cezar Dutra Fonsecs (Presidente)

Prof. Achyles Barcelos da Costa

Prof. Carlos Augusto Crusius

Prof. Claudio Francisco Accurso

Prof. Edgar Augusto Lanzer

Prof. Ernani Hickmann

Prof. Juvir Mattuella

Prof. João Rogério Sonson

Profa. Maria Imilda da Costa e Silva

Prof. Nali de Jesus de Souza

Prof. Nuno Renan L. de Figueiredo Pinto

Profa. Otilia Beatriz Kroeff Carrion

Prof. Paulo Alexandre Sphor

Prof. Roberto Camps Moraes

Profa。 Yeda Rorato Crusius

FUNDADOR: Prof. Antonio Carlos Santos Rosa

ANÁLISE ECONÔMICA publica dois números anuais nos meses de março e novembro. O preço da assinatura para 1986 é $\mathrm{Cr} \$ 20,000,00$, a ser pago através de cheque nominal para "Faculdade de Ciências Econômicas - UFRGS". Aceita-se permuta com revistas congêneres. Aceitam-se, também, livros para elaboração de resenhas ou recensões.

Toda a correspondência, material para publicação, assinaturas e permutas devem ser dirigidas a:

Prof. PEDRO CEZAR DUTRA FONSECA

Revista Análise Econômica

Avenida João Pessoa, $52-39$ andar

90.000 - Porto Alegre (RS) - Brasil 


\section{CONVERGÊNCIA, DIVERGÊNCIA E REALINHAMENTO NA TEORIA MACROECONÔMICA INGLESA*}

\section{DAVID COBHAM}

Entre os economistas ingleses que se preocupavam ativamente com os problemas macroeconômicos é provavelmente lugar-comum que, na Inglaterra, os debates básicos sobre a teoria e política macroeconômica modificaram-se acentuadamente no último decênio.

Para os economistas de outras áreas e também para os macroeconomistas não-ingleses e ainda mais para os não-economistas, estas modificações são muito menos claras e o debate econômico ccmum é ainda muitas vezes baseacio sobre a simples distinção entre keynesianos e monetaristas.

Neste artigo sustentaremos que esta simples visão da questão tornou-se dcsatualizada, indicaremos as modificações que ocorreram na teoria macroeconômica inglesa no início da década de setenta e apresentaremos alguns fatores teóricos e empíricos responsáveis por estas modificações.

Iniciaremos apresentariúo uma breve caracterização, em termos de cinco pointos chaves, do keneysianismo e do monetarismo ingleses do fim da década de sessenta e início dos anos setenta.

Sustentaremos que existiram importantes elementos de convergência sobre estes cinco pontos chaves entre keynesianos e alguns monetaristas. Os nomes mais importantes entre estes keyne-

* Agradeço a Michael Artis, David Currie, Charles Goodhart, Davi Laidler, Patrick Minford, Michael Summer e George Zis. Por seus comentários sobre uma versão preliminar do trabalho; nenhum deles, todavia, devem ser atribuídas responsabilidades por erros ou omissర̃es existentes neste trabalho.

Publicado originalmente em Moneta e Credito no 147, volume XXVII, 39 trimestre de 1984, e traduzido para o portugues por Renato Batista Masina.

ANÁLISE ECONOMICA

\begin{tabular}{l|l} 
ANO 3 & NO 5 \\
\hline
\end{tabular}

NOV./1985

p. 322 
sianos são Michael Artis, Willem Buiter, David Currie, Charles Goodhart e Marcus Miller, respectivamente. Faremos referências aos seus trabalhos. Observamos que um movimento menos amplo e menos claro numa mesma direção pode ser observado nos trabaIhos de outros economistas keynesianos, como por exemplo James Meade (1982) e seus colaboradores Vines e Maciejowski (1983). Por outro lado, entre os monetaristas, grande parte do material publicado a que nos reportaremos é de David Laidler. Apesar de sua transferência para o Canadá, Laidler continua a influenciar e a ser influenciado pelo debate econômico na Inglaterra e em muitos casos apóia teses que também são aceitas por um grupo mais amplo de economistas.

No terceiro capitulo, consideraremos outros campos em que é possível individualizar tais convergências. Em primeiro lugar, discutiremos alguns desenvolvimentos teóricos e, sucessivamente, algumas experiências da política macroeconômica inglesa que contribuíram para esta convergência.

Finalmente, no capítulo $\mathrm{V}$, observaremos as divergências in. ternas das velhas áreas do keynesianismo e do monetarismo (divergências que representam o outro lado da medalha em relação à convergência entre alguns keynesianos e alguns monetaristas); indagaremos se aqueles que estão envolvidos nas convergências estão conscientes e avaliaremos se os rótulos "keynesianos" e "monetários" continuam desenvolvendo qualquer função relevante.

O keynesianismo inglês foi tradicionalmente mais "extremista", mais "contundente" do que, por exemplo, o dos Estados Unidos. Usando a distinçāo de Coddingion (1976) cntre a versão " $\mathrm{hi}$ dráulica" do keynesianismo, a versão "funcamentalista" e a versão do "reducionismo reelaborado", a tendência "fundamentalista", com a sua mais completa e explícita rejeição da teoria das escolhas e do mecanismo de preços, foi sempre mais acentuadamente radicada na Inglaterra em Cambridge, e teve uma considerável influência na máioria mais "hidráulica" dos keynesianismos ingleses. Por outro lado, o raio da ação praticado pelo governo na utilização da tradicional política fiscal keynesiana foi sempre muito maior, por motivos constitucionais, na Inglaterra do que nos Estados Unidos. Assirn, no fim dos anos sessenta e no início dos anos setenta, o keynesianismo inglês dominante pode ser caracterizado em cinco contos. 
Em primeiro lugar, os keynesianos ingleses colocavam em dúvida que a procura de moeda fosse estável - dúvidas explícitas testemunhadas pela Comissão Radccliffe por Kaldor (1959) e por Kahn (1959) e ainda presente um decênio mais tarde, particularmente na tradição oral.

Em segundo lugar, os keynesianos colocavam em dúvida a existência de um mecanismo de transmissão da oferta de moeda à renda nominal, um argumento bastante discutido em termos da elasticidade dos investimentos em relação a taxas de juros, dúvidas estas decorrentes de trabalhos dos Oxford Studies in the Prince Mechanism sobre o comportamento dos empresários nos anos trinta (Wilson e Andrews [ 1951 ]).

Em terceiro lugar, os keynesianos em geral pretendiam que o crescimento da oferta da moeda fosse endógeno em relação à atividade econômica e à inflação, tese que foi sendo aceita sempre com maior intensidade (por exemplo, Kaldor 1970), à medida que se acumulavam resultados empíricos em favor da estabilidade da demanda por moeda.

Em termos do modelo IS-LM, estes três pontos significavam uma curva IS relativamente rígida e uma curva LM relativamente elástica, o que implica que a política fiscal é relativamente eficaz e a política monetária é relativamente fraca e que a renda é instável na presença de variações nas exportações exógenas ou dos investimentos autônomos.

Em quarto lugar, a inflação era explicada pelos keynesianos, principalmente no final da década de sessenta, após o desmentido no plano empírico da curva originária de Phillips (ainda não modificada por considerar as expectativas), exclusivamente em termos de deslocamento dos custos. Enfim, mesmo que esta seja uma característica menos importante, a maioria dos keynesianos ingleses era provavelmente a favor de câmbios fixos em lugar de flexíveis, afirmando que estes últimos seriam altamente instáveis pelo efeito da especulação desestabilizante, mas permanecendo relativamente pessimistas na sua avaliação das elasticidades envolvidas e conseqüentemente da eficácia das modificações da paridade fixa para o ajustamento do balanço de pagamentos.

Os monetaristas ingleses eram relativamente poucos no final dos anos sessenta, e no conjunto havia uma certa subordinação e dependência de Milton Friedman e de seus colegas de Chicago. No início dos anos setenta esta situação começou a mudar, quando o International Monetary Economics Research Programme da Lon. don School of Economics, sob a direção de Harry Johnson e Ale- 
xander Swoboda, e a Inflation Workshop, da Universidade de Manchester, sob a direção de David Laidler e Michael Parkin, começaram a elaborar uma versão do monetarismo apropriada a uma economia aberta, que mesmo não sendo friedmaniana em alguns aspectos importantes, era claramente importante para a economia inglesa. A posição dos monetaristas ingleses até aquele momento pode ser caracterizada em termos dos cinco pontos senguintes, correspondentes aos apresentados pelos keynesianos.

Em primeiro lugar, os monetaristas ingleses confiavam em que a demanda de moeda fosse uma função estável de um pequeno número de variáveis, com uma elasticidade relativamente baixa em relação à taxa de juros. Em segundo lugar, asseguravam a existência de um mecanismo de transmissão da oferta de moeda à renda nominal, principalmente, mas não apenas, através do efeito das variações da taxa de juros sobre os diferentes elementos do gasto (bens de consumo duráveis e investimentos).

Em terceiro lugar, eles consideravam no conjunto a oferta de moeda exógena, isto é, sustentavam que as autoridades monetárias tinham condições de controlar seu crescimento para onde o desejavam, como assim o fizeram efetivarnente. Em termos do modelo IS-LM, estes três pontos significavam uma curva LM relativamente rígida e uma curva IS relativamente elástica; o que implica que a política monetária é eficaz e a poiítica fiscal fraca, sugerindo um sistema econômico menos vulnerável do que o keynesiano, para as flutuações derivadas dos elementos exógenos da demanda.

Em quarto lugar, no início dos anos setenta os menetaristas ingleses começaram a explicar a inflação como um fenômeno de excesso da demanda em termos da curva de Phillips modificada para considerar as expectativas, com a demanda agregada dominada pelo crescimento da oferta da rnoeda, e com as expectativas de inflação que se ajusta, baseada na experiência passada.

Finalmente, mesmo se tratando de uma característica menos importante, tendiam a favorecer câmbios flexiveis baseados na consideração de que haviam concordado em isolar a economia das flutuações do resto do mundo e teriam facilitado a atuação de políticas mońetárias.

O primeiro ponto em discussão entre as posições keynesianas e monetarista acima referidas é o da estabilidade da demanda de 
moeda. No início dos anos setenta, acumulou-se uma quantidade crescente de material empírico cuja tendência era fortalecer a tese da estabilidade (por exemplo, Goodhart, Crokett, Laidler e Parkim 1970) e parecia que os economistas ingleses teriam sido forçados, neste ponto a aderir à linha monetarista. Em 1974, deslocado de modo significativo no período $1972 / 73$ - período em que foi adotado um novo sistema de controle monetário (Competition and Credit Control), a partir de setembro de 1971 e em julho de 1972 a taxa de câmbio tinha flutuado. Estes resultados empíricos poderiam ter conduzido a novas dúvidas sobre a estabilidade da demanda de moeda entre os keynesianos; efetivamente, a possibilidade da instabilidade foi levada em consideração nas duas primeiras análises sobre a questão por Artis e Lewis em 1974 e por Hoecche também em 1974. Nos seus sucessivos trabalhos (1976 e 1981), os mesmos autores Artis e Lewis tentaram explicar o aparente deslo. camento da demanda da moeda, não simplesmente através das defasagens nos ajustamentos da demanda à oferta, mas tambérn em termos de shocks na oferta da moeda que teriam constrangido o setor privado a distanciar-se do próprio elenco de procura por moeda nc curto período. Esta explicação foi posteriormente desenvolvida em tempos recentes em termos de reserva de moeda de "desequilíbrio" ou de amortecimento.

Para os fins propostos, o ponto importante a ser observado é que muitos economistas keynesianos não estão mais dispostos a refutar a proposição de que a demanda de moeda é geralmente estável no longo período, mesmo se for difícil formalizar a relação de curto período.

Também no que diz respeito ao segundo ponto em discussão, o mecanismo de transmissão, existiu um notável grau de convergência que tem levado em consideração uma série de mecanismos alternativos possiveis e particularmente, para a Inglaterra, a taxa de câmbio. Assim Laidler (1982, cap. 4) chamou a atenção sobre a conexão entre política fiscal e monetária, envolvida pelo vínculo do orçamento público e sobre as expectativas inflacionárias, enquanto Laidler, Artis e John Williamson atribuíram considerável importância à taxa de câmbio como mecanismo de transmissão no seu testemunho no Treasury and Civil Service Committeé em 1980. Modelos que envolveram este último mecanismo foram apresentados em recentes artigos de economistas keynesianos, como Artis (1979), Buiter e Miller (1981).

Os debates sobre a exogeneidade ou endogeneidade da oferta da moeda, o terceiro dos cinco pontos em discussão, diminuíram 
nos últimos anos. Isto não deve surpreender: depois de um decênio durante $o$ qual as autoridades tentaram continuadamente investir no processo de crescimento da massa monetária - esforços que foram visivelmente enérgicos mas nem sempre coroados de sucesso tornou-se muito difícil sustentar que a oferta de moeda é simplesmente endógena ou que a autoridade monetária possa controlá-la ao seu modo. Por outro lado, os recentes testes econométricos de causalidade, como os de Mills (1980), justificam a hipótese de exogeneidade em relação aos testes procedentes, como aqueles de Williams e outros (1976), assim como é reconhecido por Artis e Lewis (1981). Por sua vez, os monetaristas foram obrigados a reconhecer pelo menos algumas das dificuldades ligadas às projeções e à execução de políticas de controle monetário (por exemplo, Laidler, $1982^{b}$, p. 32-34, 161-163; Budd 1982, p. 22-28; Cobham 1982). Assim também sobre este ponto houver certa convergência para uma posição que analisa os problemas de controle monetário em vez de argumentar em favor de uma causalidade unidirecional entre oferta de moeda e renda monetária, em qualquer direção.

A controvérsia sobre as causas da inflação na macroeconomia inglesa foi, sob muitos aspectos, mais virulenta no início dos anos setenta. Para isto é tanto mais surpreendente a média em que também neste caso a intensidade dos debates foi sendo reduzida.

$O$ desenvolvimento mais importante parece ter sido a substituição, entre alguns economistas keynesianos, da hipótese da rigidez do salário monetário por aquela de resistência do salário real: esta última hipótese tem alinhado os keynesianos com a hipótese de ausência da ilusão monetária no longo período que caracteriza a análise monetária da curva de Phillips modificada púr considerar as expectativas, gerando em muitcs casos previsões comparáveis à desta última análise, como foi reconhecido por Artis e Miller (1979). Desta forma alguns economıstas keynesianos tornaram-se mais inclinados a utilizar formulações bastante próximas à da curva de Phillips, modificada por considerarem as expectativas, se bem que muitas vezes prefiram a expressão "inflação de fundo" em vez da expressão "expectativas inflacionárias" como em Buiter e Miller (1982). Ao mesmo tempo, ocorre um notável "reaparecimerito" de variáve is de demanda nos trabalhos empíricos sobre a inflação salarial (Artis e Lewis, 1983).

Por outro lado alguns monetaristas tornaram-se mais inclinados a admitir a existência de importantes efeitos de repasses de custos sobre os preços, no curto período, como fọi, por exemplo. o forte aumento do preço do petróleo nos anos setenta ou a quase 
duplicação do IVA em 1979 (Laidler 1982, p. 14.15); enquanto que Summer e Ward (1983) concluíram que apesar da evidência empírica em favor de uma curva de Phillips vertical no longo período em relação à taxa natural de desemprego, dominante nos anos setenta, esta era muito menos nítida nos anos sessenta. Também sobre este ponto houve importante convergência, se bem que não total, entre keynesianos e monetaristas.

O quinto ponto em discussão no final dos anos sessenta e início dos anos setenta era a escolha do regime de câmbio, com os monetaristas geralmente preferindo câmbios flexíveis e os keynesianos câmbios fixos. A simples argumentação originariamente proposta em favor dos câmbios flexíveis foi fortemente contestada por Mundell no âmago do mais amplo campo monetarista com uma série de artigos, alguns dos quais anteriores ao periodo de que estamos falando, por exemplo, 1969, 1973; essencialmente, em uiii mundo de mobilidade dos capitais, os câmbios flexíveis não isolam a econcmia dos "choques" reais do resto do mundo, pois a balança comercial não está vinculada em zero; enquanto zue a adoção de câmbios flexíveis não melhora o número de instrumentos de política econômica à disposição do governo, relativamente aos seus objetivos, uma vez que se reconheça o rol dos câmbios fixos ao vinculá-los ao nível de preços. Estes argumentos agora estão sendo aceitos pelos monetaristas: Laidler (1982 a, p. 165), por exemplo, depois de haver passado em revista os problemas, conclui que "a única vantagem dos câmbios flexíveis é que eles permitem a cada país possuir qualquer taxa de inflação gerada pelas próprias políticas internas". Entre os keynesianos, por outro lado, a introdução da hipótese de resistência do salário real conduziu a resultados analíticos sobre a eficácia de uma desvalorização com o objetivo de equilibrar o baianço de pagamentos e seus efeitos sobre o nível de preços que estão próximos aos obtidos através de mecanismos diferentes, no acréscimo monetário do balanço de pagamentos.

Artis e Currie, em 1979, docurientaram que os modelos do Tesouro, da London Business School e do National Institute (edição 1979) contêm uma significativa "conexão" da taxa de câmbio ao nível dos preços, uma vez que se considere a reação dos salários. O resultado é o reconhecimento de ambos os lados de que não existe nenhuma preferência geral pelos câmbios fixos ou pelos flexíveis, mas que a escolha deve ser feita na base de uma análise conjuntural (comparar a discussão de Laidler 1982 com as observaçõos de Artis 1981, sobre o desejo de participação da Inglaterra no mecanismo da taxa de câmbio do SME). Uma das 
poucas exceções a esta posição é a tese monetarista de uma economia aberta, observada por Summer e Zis 1982. Segundo os mesmos, em geral os câmbios fixos são preferidos, pelo menos pelos membros da Comunidade Européia.

E claro que sobre os cinco pontos principais de controvérsia entre os monetaristas e os keynesianos ingleses no final dos anos sessenta e início dos anos setenta houve um processo de convergência entre alguns monetaristas e alguns keynesianos, geralmente não tendendo para uma outra posição original, mas para uma terceira posição. Antes de passar para uma série de outras áreas, a propósito das quais se sustentará que um análogo processo de convergência está acontecendo, vale a pena observar que a maior parte do processo de convergência que identificamos até agora pode ser resumido em termos do conjunto de curvas de demanda e oferta agregadas do gráfico 1 (este conjunto já estava quase desaparecido na literatura em periodo precedente, mas atualmente está prevalecendo); aqui a curva de demanda agregada é tanto menos acentuadamente influenciada, se não completamente dominada, pelo crescimento monetário; as curvas de oferta agregada de longo período é vertical, enquanto aquela de curto periodo pressupõe expectativas de um nível de preços fixos ou um salário monetário fixo, deslocando-se para o alto em resposta a um aumento do nível de preços.

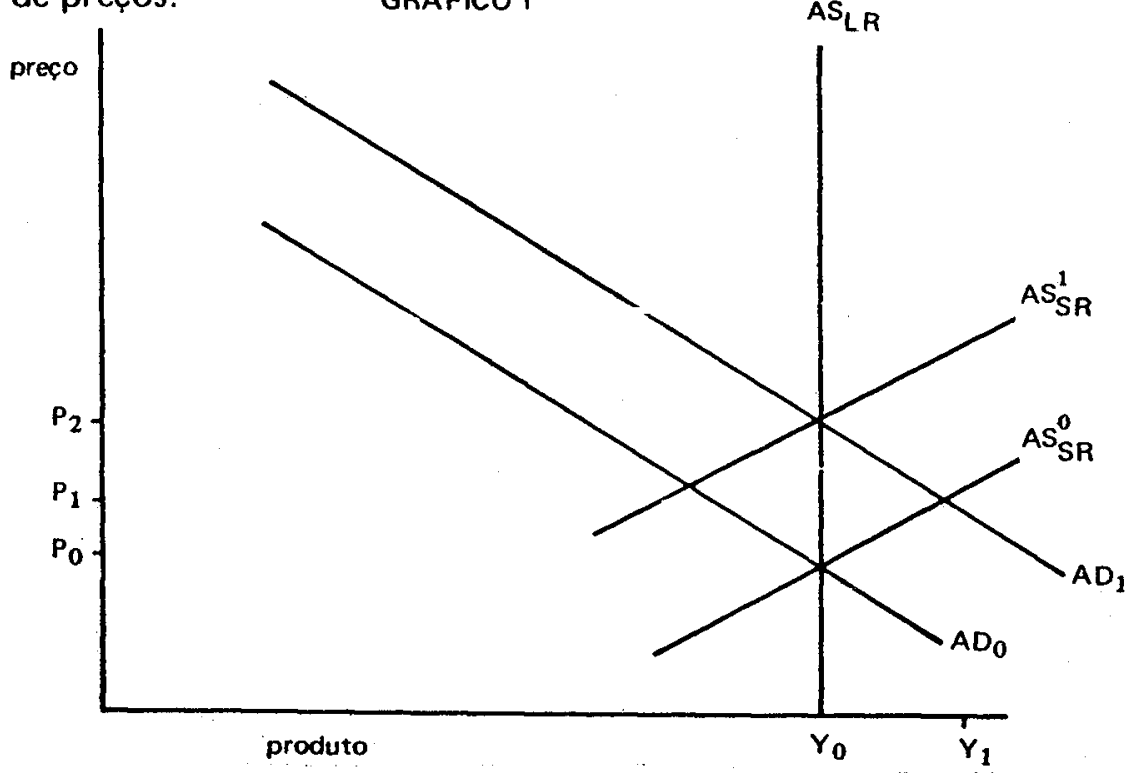

De um equilibrio inicial correspondente a $Y_{0}$ e $P_{0}$, com uma demanda agregada $A D_{0}$, com uma oferta agregada na vertical, $A S^{L R}$ 
de longo periodo e uma oferta agregada de curto periodo AS SR $_{S}$ (traçada ou por um nível de preços fixos esperados ou por um salário monetário fixo), uma política expansionista que desloca a demanda agregada para $A D_{1}$ faz com que a produção se desloque para $Y_{1}$ e os preços para $P_{1}$. Num período longo, $o$ aumento dos precos conduz a um deslocamento para o alto da curva de oferta agregada de curto período e em conseqüência a economia atinge um novo ponto de equilibrio de longo período correspondente ao nivel de preços $P_{2}$ e ao nivel inicial de produção $Y_{0}$.

\section{III}

O processo de convergência traçado no capítulo anterior pode ser observado em outras áreas da teoria e da política macroeconômica. Assim é para o posicionamento nos confrontos da "revolução das expectativas racionais" ou "nova macroeconomia clássica". Esta última, na macroeconomia inglesa, está fracamente representada; os seus adeptos mais importantes são Pạtrick Minford e seus colegas da Universidade de Liverpol (por exemplo, Minford 1980 e Minford e Peel 1981), enquanto pesquisas mais acadêmicas foram realizadas por Attfield e outros em 1981, Baillil e outros 1983 e trabalhos realizados e divulgados pela City University (ver a Economic Review da City University Business Schooll). Todavia, não existem dúvidas de que as "novas idéias clássicas" foram tomadas muito a sério pelas duas correntes de convergência em formação e atingem o posicionamento geral de ambas, caracterizado pela insistência sohre a distinção entre a hipótese das expectativas racionais em si mesmas e pela hipotese do equilíbrio perfeito do marcado (market clearing), com o qual a primeira hipótese se ajusta aos "novos modelos clássicos". Tal distincão foi feita por keynesianos norte-americanos, como por exemplo Tobim (1980 cap. 2), e é fundamental para a crítica que Laidler está desenvolvendo nos debates das idéias "neoaustríacas" (Laidler 1982b cap. 3; 1982c); esta é essencial, por exemplo, para o trabalho de Currie sobre pequenos modelos macro, trabalhos a que conduz a análise de Lucas (1976), das implicações das hipóteses das expectativas nacionais para a formalização e para a prova econométrica (Currie e Lavine 1982; Currie 1982).

Uma segunda área em que é possível observar alguma convergência é a análise da "excessiva reatividade" das taxas de câmbio. Essa análise iniciou-se com Dornbusch 1976 (monetarista de eco- 
nomia aberta que recentemente assumiu uma posição muito mais eclética; explica que em respeito a "choques" monetários e de outros tipos, as taxas de câmbio podem superar seu nível de equilíbrio de longo período, pois os mercados financeiros se ajustam rapidamente e eficazmente a expectativas que se formam "racionalmente"); enquanto que os ajustamentos nos mercados de trabalho e de bens são mais lentos, como na análise da curva de Phillips modificada para poder considerar as expectativas quando estas últimas são dominadas pela experiência passada. Desta forma, semeIhante análise se ajusta bem à convergência entre keynesianos e monetaristas. Esta foi introduzida nos debates de política econômica na Inglaterra por Niehaus (1981) e Buiter e Miller (1981 a, b), na tentativa de explicar a notável valorização da libra esterlina entre o início de 1979 e o início de 1981; mas o seu resultado fun. damental pode ser encontrado também nos modelos da London Business School (Beenstock, Budd e Warburton 1981 e também em Minford 1981). Goodhart e Temperton 1982 encontraram alguma sustentação empírica para a hipótese, contrariando as suas primeiras expectativas, e uma referência favorável pode ser encontrada em Laidler (1982b p. 167-168).

Uma terceira área de convergência é aquela das "reservas de moeda de desequilíbrio" ou "monetarismo das reservas de amortecimento": aqui encontramos dois dos mais eminentes pesquisadores sobre a demanda de moeda na Inglaterra: Goodhart e Laidler (1984), ambos desenvolvendo trabalhos no sentido de desenvolver uma teoria da demanda de moeda pela direção sugerida no contexto inglês principalmente por Artis e Lewis 1976: as reservas de moedas são consideradas nessa teoria como um resíduo ou como reserva de amortização que absorve flutuações não pievistas da renda e de gastos e que os possuidores tentam manter náo a um determinado nível (para dados de renda nominal, taxa de juro, inflação esperada, etc.) mas no interior de uma determinada zona. Goodhart é talvez o interessado nas implicaçóes de política econômica da teoria, enquanto Leidler dirige a própria análise em parte contra a hipótese da "nova macroeconomia clássica" de equil íbrio contínuo dos mercados (se os mercados estão sempre em equilibrio e os preços se ajustam instantaneamente, não existe nenhuma necessidade de reserva de amortizaçăo). Todavia este esforço comum de um importante consultor keynesiano do governo e de um importante monetarista acadêmico é uma prova irsofismável do tipo de convergência que está acontecendo. 
A tese em favor do "ajustamento da inflação" à necessidade financeira do setor público, considerando o efeito da inflação corrente sobre o valor real do estoque existente da dívida do setor público, é exemplo um pouco diferente desta convergência: aqui os keynesianos ingleses se apropriaram dos monetaristas norte-americanos, enquanto os monetaristas ingleses pouco disseram sobre o tema, pelo menos em publicações.

A tese deslanchou com as estimativas de Taylor e Theadgold (1979) da "Poupança Nacional Real" e da necessidade financeira real do setor público e foi desenvolvida por uma série de artigos de Miller (1981 e 1982). Na época em que esteve na Comissão Treasury and Civil Service (1980), Friedman especificamente avaliou as análises de Taylor em Theadgold, análises que estão estritamente ligadas às suas argumentações favoráveis à indexação e à análise monetarista dos custos da inflação em termos de bem-estar social (por exemplo, Friedman 1974); a análise também recebe apoio de Williamson, Hahn e Kaldor. Recentemente os keynesianos "convictos" como Neuburger (1983) foram tentados a fazer uso dessa análise como arma crítica contra a atual política econômica do governo. Monetaristas como Budd e Dicks (1980), todavia permaneceram céticos, enquanto Minford (1982) criticou com veemência o uso da necessidade financeira real do setor público como objetivo da política econômica.

Concluímos este parágrafo com um breve aceno a três outras áreas em que se verificaram algumas convergências. Em primeiro lugar, monetaristas como Laidler (1982b pa. 161-163) começaram a levar a sério a mais tradicional ênfase keynesiana (recentemente sublinhada pcr Goodhart 1982) sobre a modificação estrutural do sistema financeiro e o problerria que este último coloca pela definição e controle de um agregado monetário como objetivo de política econômica.

Em segundo lugar pequeno número de economistas de origem nionetarista, por exemplo Cross 1983, reconheceu a dificuldade de explicar o possível aumento da taxa natural de desemprego depois da metade da década de sessenta. Em terceiro lugar, os economistas keynesianos tornaram-se muito menos otimistas sobre as possibiiidades de "sintonizar" (fine-turning) a economia, mesmo se fossem atacaddos por qualquer forma rude de sintonização (coarse turning) (Currie 1981 p. 12). 
E possível individualizar três principais desenvolvimentos teóricos que deram importante contribuição a este processo de convergência. Em primeiro lugar, o acréscimo monetário à balança de pagamentos e, mais geralmente, o monetarismo de economia aberta, como foi desenvolvido por Johnson (por exemplo 1972, caps. 9 e 13) e sucessivamente por outros pesquisadores do LSE e Manchester (por exemplo Johnson 1976, Parkin e Zis 1976), que concordaram em construir uma análise monetarista da experiência macroeconômica inglesa que foi superior com vantagem às tentativas acanhadas (por exemplo, Harris 1975) de aplicar Friedman na Inglaterra. Particularmente, o monetarismo de economia aberta tem mostrado que com câmbios fixos a oferta de moeda é endógena e identificou-se com câmbios flexíveis, a própria taxa de câmbio co. mo um importante mecanismo de transmissão: estes dois pontos possibilitam interpretar grande parte de evidência empírica acumulada na Inglaterra de uma maneira aceitável, seja pelos keynesianos como pelos monetaristas. Por outro lado, como foi dito no capítulo II, o monetarısmo de economia aberta fornece uma crítica à tese em favor dos câmbios flexíveis, tendendo assim a resolver uma das principais controvérsias entre keynesianos e monetaristas ingleses.

Em segundo lugar, a literatura sobre o vínculo do balanço do governo tem contribuído substancialmente para a evolução do debate entre keynesianos e monetaristas nos anos 70 (veja Currie 1978 e Burrows 1979). Esta literatura por um lado tem sublinhado a interdependênciâ entre a política fiscal e a política monetária, reduzindo algumas das anteriores discussões a irrelevante significádo e, por outro lado, tem demonstrado inequivocamente que algumas das previsões originariamente feitas pelos monetaristas não podem ser deduzidas de exercícios com o modelo IS-LM (sem um estreito víncuio de pleno emprego), excluindo os casos extremos de uma curva LM vertical e/ou de uma curva is horizontal; e hoje existe uma aceitação universal de que tais casos estão excluídos de evidência empírica.

Em terceiro lugar, os trabalhadores baseados nos fundamentos microeconômicos da curva de Phillips modificada por considerar as expectativas, posteriormente aos artigos originais de Phelps (1967) e Friedman (1968) tornaram explícitos as duas interpretações alternativas disponiveis: de um lado a interpretação baseada sobre uma curva "fisheriana" de oferta agregada a qual a curva de 
Phillips mostra a reação da produção em divergência entre preços efetivos (estabelecidos por um divulgador walrasiano) e os preços esperados; por outro lado, a interpretação baseada sobre a hipótese de desequilíbrio dos mercados segundo a qual a curva demonstra a reação dos preços aos excessos de procura. E claro dos trabalhos de Laidler (1982b, caps. 1 e 4) que a distinção entre estas interpretaçőes tem contribuído no esclarecimento, como também no desenvolvimento de suas idéias, as quais são fortemente favoráveis à segunda interpretação. Este desenvolvimento oferece assim uma versão do monetarismo que é mais acessível aos economistas cuja visão é essencialmente keynesiana e ao mesmo tempo conduz a uma maior diferenciação entre monetaristas mais gradualistas, como por exemplo Laidler e monetaristas neoaustríacos ou da "nova macroeconomia clássica".

As modificações na macroeconomia inglesa sofreram muito a influência da experiência macroeconômica inglesa do último decênio. Aqui o fator mais importante foi a experiência dos câmbios flutuantes, entre outros, da desvalorização associada à políticčexpancionista do governo conservador de Heath e Barber em 1972/ 73, a prolongada crise da libra em 1976 e a substancial desvalorização da libra no início de 1979 e início de 1981. Estes desenvolvimentos tornaram os economistas keynesianos (e outros economistas) mais cientes da importância da taxa de câmbio como mecanismo de transmissão, seja pelo efeito da variação dos preços sobre os salários (levando assim ao abandono a ilusão monetária, com exceção de curto período). Por outro lado, induziram os keynesianos a serem muito mais cautelosos na medida em que políticas deflacionistas produzem efeitos sobre a produção e não sobre os preços. $E$ a volatilidade da taxa de câmbio da libra no período foi mu ito superior à dos anos 60 , esperavam os defensores dos câmbios flexíveis (veja Zis 1983); foi também difícil a formulação ou explicação (veja Hacche e Townend, 1981), tendo atenuado o entusiasmo pelos câmbios flexíveis.

Uma segunda experiência que influenciou o debate macroeconômico inglês foi a história do controle monetário na Inglaterra, particularmente nos anos posteriores a 1979. Anteriormente as dificuldades de controle monetário podiam ser explicadas em termos de falta de vontade política. Mas esta argumentação foi muito mais difícil sustentá-la sob o governo Thatcher (por esta razão foi levantado um artifício alternativo de "sabotagem ao Banco da Inglaterra".) Por outro lado os problemas de controle monetário no inícic dos anos 80 complicaram-se, por um !ado pelas imprevisíveis 
instabilidades do crédito bancário para o setor privado (mais do que pelos desequilíbrios incontrolados do setor públicol e por outro lado pelos evidentes deslocamentos seja mais de demanda das várias definições de moeda, seja nas relações entre as várias medidas da massa monetária. Assim, os monetaristas foram obrigados a reconhecer a existência de problemas que antes eram apenas considerados pelos keynesianos, enquanto que ao mesmo tempo os keynesianos foram obrigados a abandonar a hipótese de simples endogeneidade da moeda em relação aos notáveis e visíveis esforços das autoridades para controlar o crescimento monetário.

Um terceiro fator foi a experiência de uma série de políticas de rendas durante os anos 60 e 70 . Aqui também economistas com evidente incl inação a atribuir a inflação aos deslocamentos dos custos foram obrigados à conclusão de que as políticas de renda tiveram apenas efeitos espontâneos e de curto período sobre a inflação salarial (veja Henry 1981). Todavia esta experiência conduziu a outras tentativas de relacionar novas formas de políticas de rendas que possam ser menos vulneráveis aos problemas em que eram envolvidas as formas já experimentadas (por exemplo, Meade 1982). Mas, mais genericamente, contribuiu para dissipar ilusões sobre o instrumento que mais nitidamente diferenciou no passado as indicações de politica econômica dos keynesianos e dos monetaristas.

Um quarto fator é simplesmenté a gravidade da recessão 1981-82, que fez com que todos os macroeconomistas recessivos ficassem mais pessimistas e mais descrentes de curas milagrosas. Assim, entre os monetaristas é possível encontrar uma renovada insistência sobre a necessidade do gradualismo na deflação monetária (por exemplo, Budd e Dicks 1982; Laidler 1982, cap. 5). E entre os keynesianos é possivel notar uma boa dose de cautela sobre a possibilidade de medidas deflacionistas que oferecem um contraste marcante com o posicionamento confiante dos anos 60 ; por exemplo, Hopkin, Miller e Reddway, na sua "estratégia econômica alternativa" (1982), falam apenas em impedir que a desocupação cresça acima dos três milhões no primeiro ano da "estratégia", acentuando as dificuldades que se apresentam em cada política de natureza expansionista e não sugere algum dado inferior de desocupação que possa ser atingido depois de do is ou mais anos. Ao mesmo tempo a experiência de freqüentes modificações na política de balanço durante os anos 1974-77, que demonstrou a dificuldade de conduzir o "instrumento" de política fiscal, tem contribuído para tornar os keynesianos mais céticos sobre o grau de precisão com que a sconomia púde ser controlada, enquanto dificuldades seme- 
Thantes no controle de oferta monetária, nos anos seguintes, reforçaram a tradicional prudência dos monetaristas a este respeito.

\section{V}

Temos sustentado que por volta do último decênio houve um importante processo de convergência na macroeconomia inglesa entre um grupo de keynesianos e um grupo de monetaristas, um processo que relacionou uma ampla gama de prcblemas e que pode ser colocado em relação com uma série de desenvolvimentos teóricos específicos de vários aspectos da experiência de política macroeconômica inglesa daquele período. $O$ outro lado desta medaTha é naturalmente uma crescente divergência entre os economistas "convergentes" e os não "convergentes" em cada uma das áreas do keynesianismo e do monetarismo.

Dos keynesianos não convergentes o mais representativo é provavelmente Kaldor (1982) o qual demonstrou uma acentuada continuidade com o keynesianismo dos últimos anos da década de sessenta. Usando as palavras de Harrington (1983, p. 64) na apreciação conjunta de Kaldor (1982) e Laidler (1982b), "enquanto os particulares e o ponto central dos trabalhos de Kaldor são por vezes modificados sobretudo em função das modificaçoes das questões correntes de política econômica, o acréscimo teórico de fundo não é combatido". Harrington sabe também as enormes diferenças entre o monetarismo que Kaldor denuncia e o monetarismo de Laidler. Uma razão para estas diferenças é presumivelmente a incapacidade cu a renúncia de Kaldor em não fazer qualquer distinção entre os monetaristas gradualistas convergentes como Laidler e os economistas divergentes da "nova macroeconomia clássica", como Minford lembrava no capitulo III. Enquanto é possívol pensar que os keynesianos não convergentes permaneceram estáveis num mundo que avançava, os monetaristas não convergentes da "nova macroeconomia clássica" deveriam talvez ser vistos como separados por uma tangente, caracterizada por um equilibrio permanente dos mercados e uma saliente persistência pelo lado de oferta.

Ocorre assim redesenhar o "mapa" da macroeconomia inglesa, substituindo a velha com o seu bipolarismo keynesiano-monetarista por uma nova em que se individualizam três pólos: os keynesianos tradicionais como Kaldor, a convergência em andamento en. tre keynesianos e monetaristas, demonstrada neste artigo, e os eco- 
nomistas da "nova macroeconomia clássica" representados por Minford. Neste ponto, todavia, aparecem outros problemas: em primeiro lugar, os participantes do processo de convergência reconheceriam a descrição apresentada aqui? e não seria melhor repelir para sempre as denominações "keynesianos" e "monetaristas" , inúteis e desatualizadas?

Com relação à primeira questão, existem numerosas provas de que os economistas envolvidos no processo de convergência estão bem a par do que está acontecendo. Pelo lado dos keynesianos, Currie (1981, p. 2) observou que os "keynesianos foram lentos em adaptar seu pensamento no mundo flutuante dos anos 70, mas afirmou que "a lição de que a moeda possui ịmportância vital num mundo de taxas de câmbio flutuante foi muito bem considerada para que fosse esquecida". E Goodhart conclui em seu artigo de 1984 com a esperança de que o enfoque monetário do desequilibrio "possa servir como ponte entre as metodologias keynesianas e monetaristas". Para os monetaristas, Budd e outros (1984) propuseram uma definição do monetarismo, sobre a base da qual sustentam que Artis e Currie (1981), Buiter e Miller (1981) e também Modigliani (1977) deveriam ser classificados como monetaristas. $E$ Laidler (1982b, p. IX afirmou que “o monetarismo, ao qual este livro é dedicado, está nos seus fundamentos teóricos mais próximo da economia keynesiana do que a denominada "nova economia clássica". Segundo Laidler e Bentley (1983, p. 33) "é difícil dizer se o nosso modelo deve ser definido como keynesiano ou monetarista". Desta fica claro que todos aqueles que estão envolvidos na convergência não são mienos esclarecidos.

Mas isto significa que as denominações "keynesiano" e "monetarista" devem ser eliminadas? Por um lado o processo de convergêiricia está ainda incompleto e na medida em que as denominações indicam as origens intelectuais dos economistas, individualizam alguma coisa que continuará ainda a ter importância no tempo: de certa forma o que é visto é condicionado pelo que já foi visto. Por exemplo, os monetaristas convergentes provavelmente darão maior importância à moeda em relaçăo a outras atividades e têm demonstrado pouca disposição em abandonar os principios de controle da base monetária. Por outro lado, tendo em vista o realinhamento que já ocorreu é assim mesmo decididamente incorreto usar a mesma denominação para Kaldor e Currie ou para Laidler e Minford. Assim, as velhas denominações dizem alguma coisa de útil sobre as diversas correntes "no interior" da convergência, mas são inúteis para descrever no conjunto o mapa. $O$ objetivo de usar 
denominações é, em primeiro lugar, chamar a atençã்o, ordenar e esclarecer um debate ou um conjunto de debates a um determinado estágio. Mas quando os debates são procedentes, a manutenção das denominações confunde e dificulta. No final é preferivel libertar-se das duas denominações "monetaristas" e keynesianos"; enquanto que para as áreas não convergentes poderia ser usada a expressão "keynesiano tradicional" ou "nova macroeconomia clássica" e os economistas da convergência poderiam ser definidos como "monetaristas de desequilíbrio".

\section{BIBLIOGRAFIA}

ARTIS, M.J. (1981), "From monetary to exchange rate targets", in Banca Nazionale del Lavoro Quarterly Review n. 138, pp. 339-358.

ARTIS, M.J. e D.A. CURRIE (1979), "Monetary and exchange rate targets", ciclostilato, Università di Manchester.

ARTIS, M.J. E D.A. CURRIE (1981), "Monetary and exchange rate targets: a case for conditional targets", in Eltis e Sinclair (1981).

ARTIS, M.J. e M.K. LEWIS (1974). "The demand for money: stable or unstable", The Banker, marzo.

ARTIS, M.J. e M.K. LEWIS (1976). "The demand for money in the UK, 1963-73", Manchester School, n. 44, pp. 147-181.

ARTIS, M.J. e M.K. LEWIS (1981), Monetary Control in the United Kingdom, Oxford, Philip Allan.

ARTIS, M.J. e M.K. LEWIS (1983), "Inflation in the United Kingdom", ciclostilato, Università di Manchester e Adelaide.

ARTIS, M.J. e M. MILLER (1979), "Inflation, real wages and the terms of trarie", in J. Bowers, curatore, Inflation, Development and Integration, Leeds University Press.

ATTFIELD, C.L.F., D. DEMERY e N.W. DUCK (1981), "Unanticipated monetarv growh, output and the price level: U.K. 1946-77", European Economic Review, n. 16, pp. 367-385.

BAILLIE, R.J., R.E. LIPPENS e P.C. MCMAHON (1983), “Testing rational expectations and efficiency in the foreign exchange market", Econometrica, n. 51, pp. 553-563.

BEENSTOCK. M., A. BUDD e P. WARBURTON (1981), "Monetary policy, expectations and real exchange rate dynamics", in Eltis e Sinclair (1981).

BUDD, A. (1982). "The economy after the 1982 budget", in Kay (1982).

BUDD, A. e G. DICKS (1980). "The budget, the PSBR and the money supply", Economic Outlook (London Business School), febbraio.

BUDD, A. e G. DICKS (1982). "The costs and benefits of cutting inflation", Economic Outlook (London Business School), ottobre.

BUDD, A., S. HOLLY, A. LONGBOTTOM e D. SMITH (1984), “Does monetarism fit the UK facts?", in B. Griffiths e G. Wood, curatori, Monetarism in the United Kingdom, Londra, Macmilian.

BUITER, W.H. e M. MILLER (1981a), "Monetary policy and international competitiveness: the problem of adjustment", in Eltis e Sinclair (1981). 
BUITER, W.H, e M. MILLER (1981b). "The Thatcher experiment : the first two years"., Brookings Papers on Economic Activity, 19812 , pp. 315-367.

BUITER. W.H. e M. MILLER (1982), "Real exchange rate overshooting and the output cost of bringing down inflation", European Economic Review, n. 18, pp. 85-123.

BURROWS, P. (1979). "The government budget constraint and the monetarist-Keynesian debate", in S.T. Cook e P.M. Jackson, curatori, Current Issues in Fiscal Policy, Oxford, Martin Robertson.

COBHAM, D. (1982). Domestic Credit Expansion, the Balance of Payments and Exchange Rate, and Inflation: Some Aspects of U.K. Monetary Policy, 1963-78, tesi di Ph. D., Università di Manchester.

CODDINGTON, A. (1976), "Keynesian economics: the search for first principles", Journal of Economic Literature, n. 14, pp. 1258-1273.

CROSS, R.B. (1983), "Long term unemployment, hysteresis and the natural rate of unemployment", Business Economist, n. 14, estate.

CURRIE, D.A. (1978), "Macroeconomic policy and government financing", in M.J. Artis e A.R. Nobay, curatory, Contemporary Economic Analysis, Londra, Croom Helm.

CURRIE, D.A. (1981), "Monetarist policies and neo-Keynesian alternatives", Thames Papers in Political Economy.

CURRIE, D.A. (1982), "The monetarist policy rule: a critique", in Banca Nazionale del Lavoro Quarterly Review, n. 142, pp. 335-346.

CURRIE, D.A. E P. LEVINE (1982), "Stochastic macroeconomic policy simulations for a small open economy", ciclostilato, Queen Mary College, Londra.

DORNBUSCH, R. (1976). "Expectations and exchange rate dy namics", Journal of Political Economy, n. 84, pp. 1161-1176.

ELTIS, W.A. E P.J.N. SINCLAIR, (1981), The Money Supply and the Exchange Rate, Oxford University Press.

FRIEDMAN, M. (1968), "The role of monetary policy". American Economic Review, $\mathrm{n}$ 58, Pp. $1-17$.

FRIEDMAN, M. (1974), Monetary Correction, Londra, Institute of Economic Affairs.

GOODHART, C.A.E. (1984), 'Disequilibrium money - a note', Cap. $X$ di Monetary Theory and Practice, Londra, Macmillan.

GOODHART, C.A.E. (1982), "Structural changes in the banking system and the determination of the stock of money", ciclostilato, Banca d'inghilterra.

GOODHART, C.A.E E A.D. CROCKETT (1970), "The importance of money" , Bank of England Quarterly Bulletin, n. 10, pp. 159.198.

GOODHART, C.A.E. E P. TEMPERTON (1982), 'The UK exchange rate, 1979-81 : a test of the overshooting hypothesis?, ciclostilato, Banca d'Inghilterra.

HACCHE, G. (1974), "The demand for money in the United Kingdom: experience since 1971 ". Bank of England Quarterly Bulletio, n. 14, pp. 224-305.

HACCHE, G. e J. TOWNEND (1981), "Exchange rates and monetary policy: modelling sterling's effective exchange rate, 1972-80", in Eltis e Sinclair (1981).

HARRINGTON, R.L. (1983), "Monetarisms: real and imaginary", Manchester School, n. 51, pp. 63-71.

HARRIS, R. (1975), "A self-confessed monetarist... ?". in British Economic Policy 1970.74, Londra, Institute of Economic Áffairs.

HENRY, S.G.B. (1981). "Incomes policy and aggregate pay", in J.L. Fallick and R.F. EIliott, curatori, Incomes Policies, Inflation and Relative Pay, Londra, Allen e Unwin.

HOPKIN, B. M. MILLER e B. REDDAWAY (1982). "An alternative economic strategy - a message of hope", Cambridge Journal of Economics, n. 6, pp. 85-103. 
JOHNSON, H. (1972), Macroeconomics and Monetary Theory, Oxford, Aldine.

KAHN, R.F. (1959). "Memorandum of evidence submitted to the Radcliffe Committee", in Committee on the Working of the Monetary System, Principal Memoranda of Evidence, Londra, HMSO.

KALDOR, N. (1959), "Monetary policy, economic stability and growth", in Committee on the Working of the Monetary System, Principal Memoranda of Evidence, Londra, HMSO.

KALDOR, N. (1970). "The new monetarism", Lloyds Bank Review, luglio.

KALDOR, N. (1982), The Scourge of Monetarism, Oxford University Press.

KAY, J., curatore, (1982), The 1982 Budget, Oxford, Blackwell.

LAIDLER, D. (1982a). "The case for flexible exchange rates in 1980", in M.T. Sumner e G. Zis, curatori, European Monetary Union, Londra, Macmillan.

LAIDLER, D. (1982b), Monetarist Perspectives, Oxford, Philip Allan.

LAIDLER, D. (1982c), "Did macroeconomics need the rational expectations revolution?", Working Paper 8215C, Department of Economics, University of Western Ontario.

LAIDLER, D. (1984). "The buffer stock' notion in monetary economics", Economic Journal, n. 84, supplemento, pp. 17-34.

LAIDLER, C. e B. BENTLEY, (1983), "A small macro-model of the post-war United States", Manchester School, n. 51, pp. 317-340.

LAIDLER, D. e M. PARKIN (1983), "The demand for money in the UK 1955-67: preliminary estimates", Manchester School, n. 38, pp. 187-208.

LUCAS, R.E. (1976), "Econometric policy evaluation: a critique"; Carnegie-Rochester Conference Series on Public Policy, 1.

MEADE, J.E. (1982), Stagflation. Volume 1: Wage Fixing, Londra, Allen e Unwin.

MILLER, M. (i981), "the medium term financial strategy: an experiment in co-ordinating monetary and fiscal policy". Fiscal Studies, n. 2, pp. 50-60.

MILLER, M. (1982), "Inflation - adjusting the public sector financial deficit", in Kay (1982).

MILLS, T.C. (1980). "Money, income and causality in the UK: a look at the recent evidence", Buhletin of Economic Research, n, 32, pp. 18-28.

MINFORD, P. (1980), "A rational expectations model of the UK under fixed and floating exchange rates", Carnegie-Rochester Conference Series on Public Policy, n. 12.

MINFORD, P. (1981), "The exchange rate and monetary policy", in Eltis e Sinclair (1981).

MINFORD, P. (1982). "The development of monetary strategy", in Kay (1982).

MINFORD, P. E D.A. PEEL (1981), "Is the government s economic strategy on course?", Lloyds Bank Review, aprile.

MODIGLIANI, F, (1977), "The monetarist controversy or, should we forsake stabilization policies?" American Economic Review, n. 67, p. 1-19.

MUNDELL, R.A. (1969), "Towards a better int ernational monetary system". Journal of Money, Credit and Banking, n. 1, pp. 625-649.

MUNDELL, R.A. (1973), "Uncommon arguments for common currencies", in H.G. Johnson e A.K. Swoboda, curatori, The Economics of Common Currencies, Londra, Allen e Unwin.

NEUBURGER, H. (1983), "Turning the clock back?" in J. Kay, curatore, The Economy and the 1983 Budget, Oxford, Blackwell.

NIEHANS, j. (1981), "The appreciation of sterling - causes, effects, policies", ciclostilato, Money Study Group.

PARKIN, M. e G. ZIS, curatori (1976), Inflation in Open Economies, Manchester University Press. 
PHELPS, E.S. (1967). YPhillips curves, expectations of inflation and optimal unemployment over time" Economica, n. 34, pp. 254-281.

SUMNER, M.T. e R. WARD (1983), "The reappearing Phillips curve", Oxford Economic Papers, n. 35, pp. 306-320.

SUMNER, M,T. e G. ZIS (1982). "On the relative inflation bias of flexible exchange rates", in Sumner e Zis, curatori, European Monetary Union, Londra, Macmilan.

TAYLOR, C., e A. THREADGOLD (1979), "'Real' national savings and its sectoral composition", Bank of England Discussion Paper n. 6.

TOBIN, J. (1980), Asset Accumulation and Economic Activity, Oxford, Blackwell.

TREASURY and CIVIL SERVICE COMMITTEE (1980), Memoranda on Monetary Po. licy, volumi 1 e 2, Londra, HMSO. (Include note di M. Artis, M. Friedman, F. Hahn, D. Laidler, N. Kaldor e J. Williamson).

VINES, D. e J. MACIEJOWSKI (1983), Stagflation. Volume 2: Demand Management, Londra, Allen e Unwin.

WILLIAMS, D., C.A.E. GOODHART E D. GOWLAND (1976), "Money, income and causality: the UK experience", American Economic Review, n. 66, pp. 417-423.

WILSON, T. e P.W.S. ANDREWS (1951), Oxford Studies in the Price Mechanism, Oxford University Press.

ZIS, G. (1983) "Exchange rate fluctuations: 1973-82", National Westminster Bank Quarterly Review, agosto. 